\title{
RETROPERITONEAL BENIGN FIBROUS HISTIOCYTOIMA-A CASE REPORT
}

KEY WORDS: Benign fibrous histiocytoma,soft tissue tumour, Retroperitoneal tumour, surgical removal

\section{Dr.G.konda reddy \\ Dr.Sowda pavani lakshmi*}

\section{Dr.Y.Narendra}

\section{Dr.Pradeep.K}

\section{Dr.C.Mahesh kumar Raju}

Assistant professor in department of general surgery,Kurnool medical college\&Hospital, Kurnool

junior resident in department of general surgery,Kurnool medical college\&Hospital, kurnool. *Corresponding Author

junior resident in department of general surgery,Kurnool medical college\&Hospital, kurnool.

junior resident in department of general surgery,Kurnool medical college\&Hospital, Kurnool

junior resident in department of general surgery,Kurnool medical college\&Hospital, kurnool

Benign fibrous histiocytomas are common soft tissue tumours located anywhere in the body but most commonly found in skin. These are slow growing tumours common in all races and all ages but most common age group is 20 to 49 years with female preponderance. In our case a 27 -year-old female with complaints of abdominal pain underwent an ultrasound abdomen and pelvis in which a retroperitoneal tumour was diagnosed. Except for abdominal pain no other complaints were noted she was well preserved. we have done an exploratory laparotomy with excision of tumour and specimen sent for Histopathological examination in which it is confirmed as benign fibrous histiocytoma. Post-operative period uneventful and she recovered well. It is rare site for the occurrence of the histiocytoma.

\section{INTRODUCTION}

Benign fibrous histiocytomas are common soft tissue tumours located anywhere in the body but most commonly found in skin and subcutaneous tissues, a deeper location being exceptional.

These are slow growing tumours common in all races and all ages but most common age group is 20 to 49 years with female preponderance.

Retroperitoneal tumours are extremely rare neoplasias, malignant in about $85 \%$ cases $35 \%$ of which are sarcomas.

They are usually clinically silent entities until size causes a shift or compression of other organs which cause the clinical signs and symptoms.

In many cases, the neoplasia is detected by ultrasound. Computerized Axial Tomography is the technique that provides more data for the establishment of diagnosis, although for many authors Nuclear Magnetic Resonance can be more defining.

The primary therapy is surgical removal, but relapses can occur if full excision is not achieved.

\section{Case presentation}

A 27 year old female was referred to Department of general surgery for further evaluation of an retroperitoneal mass which was diagnosed on an ultrasound abdomen.she had visited her gynaecologist with complaint of pain abdomen for 1 month. No any other associated symptoms were noted and after ultrasound finding of abdominal mass she was referred. She was visiting her gynaecologist randomly since 6 months for planning her second pregnancy. No complaints of menstrual irregularities or any other associated complaints. Her first born was a female child of age 5 yrs was healthy and well nourished. She had ultrasound pelvis for once in that 6 months to rule out any ovarian or uterine pathology but the scan was unremarkable. Now she underwent ultrasound abdomen and pelvis for pain abdomen which has shown a abdominal tumour of size $9.1 * 8.8 \mathrm{~cm}$ with few cystic areas in subhepatic region arising from retroperitoneum.

\section{Examination \& Investigations}

On physical examination pallor noted and on abdominal examination no inspectatory findings were noted on palpation a vague mass was palpated in the right hypochondrium extending towards epigastrium, no tenderness noted and no evidence any palpable lymph nodes. Her routine blood investigations were normal and chest $\mathrm{x}$ - ray appeared normal. On CECT abdomen a $10 * 8 \mathrm{~cm}$ heterogenous solid lesion with cystic areas noted in the right extra renal region with displacement of IVC to left.Upper GI Endoscopy was normal. MR abdomen shows evidence of large well defined lesion with heterogeneous intensity on T1,T2 sequences measuring $99 * 79 * 132 \mathrm{~mm}$ involving retroperitoneum in right paravertebral region. The lesion extending from subhepatic space superiorly upto below the region of the right kidney. The plan of management includes optimisation of haemoglobin and preparing the patient for surgery with The treatment of choice was surgical resection of tumour with histopathological examination of specimen.

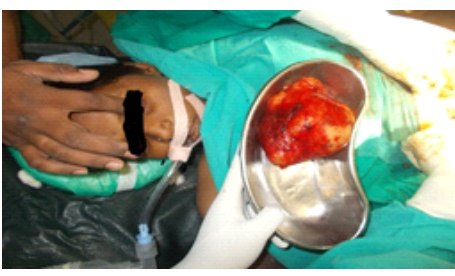

\section{DISCUSSION}

Various types of soft tissue fibrohistiocytic tumors have been examined and described by various authors, granuloma is the most frequent among those which can rarely affect the retroperitoneal space.A histiocytoma is defined, according to Kaufmann and Stout, 17 as a tumor composed of histiocytes closely grouped in a mosaic pattern, with scarce or absent intervening stroma. The cells have an abundant eosinophilic cytoplasm with lipid-containing vacuoles. Inflammatory cells are frequently present. Benign histiocytomas are by far more 
frequent than the malignant variant. According to us, certain points merit discussion and emphasis in regard to the diagnostic criteria and classification of the soft tissue fibrohistiocytic tumors. We wish to emphasize that in terms of two aspects- namely, the anaplasia of the cellular stroma and the storiform pattern-these tumors should be evaluated more precisely and definitely.

\section{CONCLUSION}

In conclusion regardless how important it is to define the benignity or malignancy of these tumors, we are of the opinion that it is most difficult to delineate this fact solely on the basis of morphological criteria. Our policy is to be very cautious and even reluctant to assess the malignancy of those tumors whose nature and behavior are not clearly defined, mainly because of the therapeutic implications. We feel that a very close cooperation between the pathologist and the oncologist would be most useful for a comprehensive diagnostic evaluation of each case and for the assessment ,of the treatment procedures.

HPE report showed spindle shaped cells arranged in fascicles and storiform pattern admixed with dilated congested blood vessels , cystic spaces and focal aggregates of xanthomatous cells. No evidence of atypia , mitosis or necrosis suggestive of benign fibrous histiocytoma.

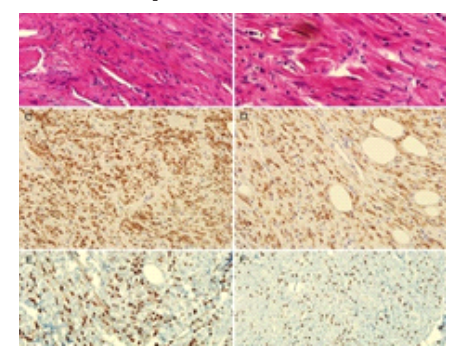

\section{REFERENCES}

1. Fletcher CDM, Unni KK, Mertens F (2002) WHO pathology and genetics of tumours of soft tissue and bone, chap 13. IARC Press, Lyon, pp 291-296 2. Singh B, Shaha A, Har-el G. Malignant fibrous histiocytoma of the head and neck. J Craniomaxillofac Surg. 265. doi: 10.1016/S1010-5182(05)80044-73. Otsuka K, Hamakawa H, Sumida T, Tanioka H. Treatment of mandibular malignant fibrous histiocytoma during pregnancy. J Oral Maxillofac Surg. 2001;59:220-224. doi: 10.1053/joms.2001.20505. 4. Skoulakis CE, Papadakis CE, Datseris GE, Drivas EI, Kyrmizakis DE, Bizakis JG. Subcutaneous benign fibrous histiocytoma of the cheek. Case report and review of the literature. Acta Otorhinolaryngol Ital. 2007;27:90-93. 5. Enzinger FM, Weiss SW (1995) Benign fibrohistiocytic tumors 